\title{
MENCARI LANDASAN HUKUM PEMBENTUKAN BADAN PENYANGGA (AGGREGATOR) GAS ALAM
}

\author{
Junaidi Albab Setiawan \\ Advokat/Kandidat Doktor Fakultas Hukum \\ Universitas Gadjah Mada Yogyakarta \\ Email: albabsetiawan@gmail.com
}

\begin{abstract}
ABSTRAK
Aggregator bergerak menjalankan fungsinya di bidang kegiatan hilir gas dimulai sejak gas dipasarkan ke pasaran dalam negeri. Gas tersebut terdiri dari gas yang dihasilkan dari kegiatan ekploitasi dari sumber dalam negeri maupun gas yang dihasilkan dari impor. Gas produksi dalam negeri maupun gas yang diimpor dari luar negeri memiliki perbedaan harga beli. Perbedaan ini berakibat kepada perbedaan harga jual kepada konsumen, baik konsumen rumahan maupun perusahaan dan industri. Demikian halnya berimbas kepada ketidakadilan bagi konsumen yang berdomsili jauh dari pusat suplai gas dan belum memiliki sarana distribusi yang memadai, karena mereka akan terkena dampak dari tingginya harga. Terlebih lagi kebijakan distribusi migas selama ini masih terpusat di lokasi lokasi yang dekat dengan kota-kota besar dan telah memiliki jaringan distribusi. Oleh karenanya maka negara membentuk aggregator (aggregator) gas yang berfungsi untuk membeli gas dari produsen dari sumber gas dalam negeri dan import migas dari luar. Gas dari berbagai sumber selanjutnya dijual kepada konsumen dengan harga rata-rata sama kepada konsumen
\end{abstract}

Kata Kunci: Aggregator, Gas Alam, Migas

\section{ABSTRACT}

The aggregator implements its functions in the gas activities downstream since the gas sold in the domestic market. The gas consists of both the local resources exploitation and the foreign production. There is a different purchase price among the local resources gas and the international production gas. This variance resulted from the difference in the selling price to the consumers, in which the home, enterprise, and industry users. Furthermore, this difference leads to injustice to the consumers who are living away from the central of gas supply and do not have adequate distribution facilities. They will be affected by the high price of the gas. Moreover, the oil and gas distribution policy are still centered in the nearby town region that has a network of distribution. Therefore, the state formed the gas aggregator that is used to purchase gas from domestic resources gas and the international production gas producers. The following gas from various sources will be sold to consumers at the equal price.

Keywords: Aggregator, Natural Gas, Oil and Gas

\section{A. LATAR BELAKANG}

Pemerintah dan DPR RI sedang menyiapkan draf Rancangan Undang-Undang (RUU) Minyak Bumi dan Gas Alam (Migas). Revisi Undang-Undang Migas masuk 
dalam Program Legeslasi Nasional (Prolegnas) tahun 2015. Semula RUU Migas ini tercatat sebagai inisiatif DPR, namun ternyata DPR tidak siap dan tahun 2016 akan dirubah menjadi RUU inisiatif pemerintah karena ternyata pemerintah lebih siap menyajikan RUU ini. Saat ini pemerintah mulai mensosialisasikan draf RUU kepada publik dalam berbagai forum terbatas di kampus-kampus maupun kepada kalangan terbuka, termasuk mulai membahasnya dengan DPR RI.

Pada rapat kerja dengan Komisi VII DPR RI, Menteri ESDM memaparkan draf revisi UU Migas yang disusun Pemerintah. Menurut pemikiran pemerintah, penyusunan Rancangan Undang-Undang ini dilatar belakangi oleh keinginan untuk memberikan kepastian hukum, memperbaiki iklim investasi, dan meningkatkan ketahanan energi (Partowidigdo, 2008: 23). Draf RUU Migas versi pemerintah tersebut mengatur tiga hal pokok tentang kegiatan hulu, hilir, dan pembentukan aggregator gas sebagai badan atau lembaga baru yang diusulkan oleh RUU ini.

Gas alam adalah komponen vital untuk suplai energi dunia. Gas alam merupakan sumber penting untuk produksi, baik bahan bakar maupun amonia yang merupakan komponen vital untuk produksi pupuk. Berdasarkan BP Statistical Review of World Energy tahun 2011, bahwa komposisi kebutuhan energi dunia bertumpu kepada 33,07 \% Minyak, 30,34 Batubara, 23,67 \% Gas, 4,88 \% Nuklir, 6,45 $\%$ Air, 1,56 energi terbarukan (Rianto, 2012; 34). Jika dilihat dari cadangan gas dunia keseluruhan maka Indonesia memiliki cadangan gas terbesar ke 14 di dunia (http:katadata.co.id, diakses pada tanggal 25 Juli 2016).

Pemanfaatan energi gas alam di Indonesia relatif stabil karena produksi gas alam berorientasi ekspor, ditambah konsentrasi, tradisi, dan kebiasan serta peralatan yang digunakan masyarakat masih cenderung peralatan yang menggunakan sumber energi BBM. Penggunaan Gas alam sebagai sumber energy belum mendapatkan perhatian yang serius (LIPI, 1977: 3). Hal ini bisa dilihat dari tabel perbandingan produksi dan konsumsi gas di Indonesia.

Daftar Produksi dan Konsumsi Gas di Indonesia 2005-2014

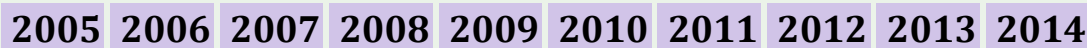

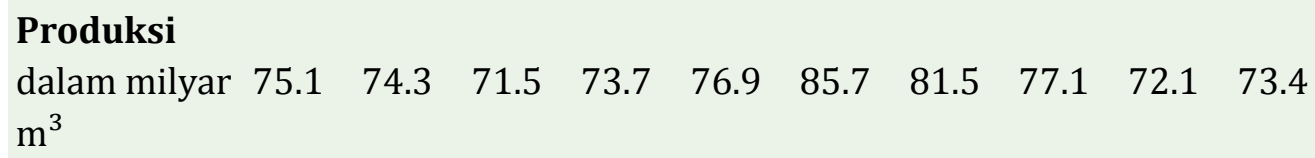

Sejak kurun waktu tahun 2012, seiring dengan upaya konversi Minyak tanah (mitan) ke Gas dan upaya lain untuk mengurangi ketergantungan terhadap BBM menjadi gas, maka hingga tahun 2025 akan mengalami peningkatan kebutuhan yang cukup signifikan terhadap gas alam. Pada periode tersebut gas alam dioptimalkan penggunaannya di dalam negeri, baik sebagai bahan bakar maupun bahan baku 
industri, serta sebagai jembatan untuk mempersiapkan penggunaan teknologi yang lebih bersih seperti energi baru dan terbarukan (http://www.migas.esdm.go.id, diakses pada tanggal 21 maret 2016).

Pada tahun 2014, total pasokan gas Indonesia mencapai 6.970 yang berasal dari pasokan eksisting 6.764 dan pasokan project 206. Tahun berikutnya, pasokan eksisting mengalami penurunan 106 menjadi 6.658 dan pasokan project meningkat 704 menjadi 910. Pada tahun 2015, terdapat pasokan potensial, sehingga total pasokan gas mencapai 7.569.

Berdasarkan gambaran pasokan dan kebutuhan gas tahun 2014 dan 2015, terlihat adanya selisih yang cukup tajam. Pada tahun 2014, selisih pasokan dan kebutuhan gas mencapai 2.524 dan pada tahun 2015 turun menjadi 2.044 karena turunnya ekspor. Potret pasokan dan kebutuhan gas 5 tahun mendatang masih diwarnai tingkat defisit yang tinggi. Selisih pasokan dan kebutuhan gas tahun 2019 diperkirakan meningkat pada tahun 2020. Hal ini disebabkan terus menurunnya jumlah pasokan. Pada tahun 2019, diperkirakan akan mengalami penurunan sebesar 33\% dari pasokan eksisting pada tahun 2014. Pasokan gas tahun 2019 ditopang oleh kenaikan pasokan project dari 206 pada 2014 menjadi 3.910. Ada pula tambahan dari pasokan potensial sebanyak 59 yang menjadikan pasokan gas secara keseluruhan pada tahun 2010 sebesar 8.445. Proyeksi produksi gas di atas menyiratkan gambaran bahwa produksi gas di masa depan akan semakin meningkat begitupun tingkat kebutuhan. Gas secara berangsur-angsur akan menjadi sumber energi utama menggantikan BBM.

Selama ini pemanfaatan gas alam digolongkan dalam tiga kelompok; Pertama, gas alam sebagai bahan bakar atau sumber energi yang digunakan sebagai bahan bakar pembangkit listrik tenaga gas atau uap, bahan bakar industri ringan, menengah, dan berat, bahan bakar kendaraan bermotor, dan bahan bakar rumah tangga. Kedua, gas alam sebagai bahan baku, selain sebagai sumber energi, gas alam dimanfaatkan sebagai bahan baku beberapa produk, seperti pupuk, petrokimia, methanol, dan plastik. Ketiga adalah gas alam sebagai komoditas ekspor dalam bentuk LNG (IPB Press, 2012: 12).

Keberadaan aggregator belum dikenal dalam undang-undang migas sebelumnya. Sehingga keberadaannya masih menimbulkan berbagai pertanyaan, terutama pertanyaan legal formal dan operasional. Tulisan ini bermaksud untuk menjawab pertanyaan-pertanyaan tersebut, terutama menyangkut aspek-aspek dasar keberadaan Aggregator gas nasional, yang meliputi

1. Apakah dasar hukum keberadaan aggregator gas?

2. Apakah peran dan fungsi aggregator gas dalam tata kelola gas?

B. PEMBAHASAN

1. DASAR HUKUM KEBERADAAN AGGREGATOR GAS

Pengertian gas alam menurut UU Migas No 22 tahun 2000, Pasal 1 angka 2 adalah hasil proses alami berupa hidrokarbon yang dalam kondisi tekanan dan temperatur atmosfer berupa fase gas yang diperoleh dari proses penambangan 
minyak dan gas alam. Gas alam atau yang sering juga disebut sebagai gas rawa, adalah bahan bakar fosil berbentuk gas yang terutama terdiri dari metana Ch4. Ia dapat ditemukan di ladang minyak, ladang gas alam. Mirip dengan minyak mentah dan batubara, gas alam adalah bahan bakar fosil yang berasal dari sisa-sisa tanaman, hewan dan mikroorganisme yang tersimpan dalam di bawah tanah selama jutaan tahun. Namun tidak seperti bahan-bahan bakar fosil lainnya, gas alam adalah salah satu sumber energi yang paling bersih (memiliki intensitas karbon yang rendah), teraman, dan paling berguna dibanding semua sumber energi lain (http://www.indonesia-investments.com/id/bisnis/komoditas/gas-alam).

Literatur lain menyebutkan, gas alam didefinisikan sebagai bahan bakar fosil berbentuk gas, tidak berwarna dan tidak berbentuk namun memiliki efek yang mengandung energi. Gas alam merupakan campuran hidrokarbon yang mempunyai daya kembang besar, daya tekan tinggi, berat jenis spesifik yang rendah dan secara alamiah terdapat dalam bentuk gas. Pada umumnya, gas alam terkumpul di bawah tanah dengan berbagai macam komposisi yang terdapat dalam kandungan minyak alam (associated gas). Semua kandungan minyak alam berkaitan dengan gas alam, di mana gas itu larut dalam minyak mentah dan seringkali membentuk "cungkup gas" (gas cap) di atas kandungan minyak alam tersebut baik di darat maupun di dasar laut. Selain itu, gas alam juga dapat berkumpul pada tambang batubara dan ladang gas alam (Richarg, 2012: 87).

Sementara itu, untuk menemukan aggregator khas Indonesia, perlu mengambil definisi tentang aggregator dari berbagai sumber. Demikian sehingga mendapatkan "daya beli" untuk meminta harga termurah untuk gas alam kelompok dan/atau kebutuhan listrik. Hal ini disebut Governmental Aggregation (http://www.puco.ohio.gov, diakses pada tanggal 16 Maret 2016). Berdasarkan contoh tersebut maka definisi aggregator kurang lebih adalah (http://www.qvinta.com, diakses pada tanggal 16 Maret 2016):

"A broker that acts on behalf of a group or groups of customers. Typically, an aggregator will set up arrangements with members of groups such as homeowner associations, affinity groups (religious, cultural, regional, and fraternal, etc.) and seek rate offers from suppliers for these 'bundled' groups of customers. Customers typically do not pay for the aggregator's services, and are not contractually required to accept the supplier offers that the aggregator finds. The possible advantage is that the aggregator can offer a larger customer pool to the supplier, and may be able to get more competitive offers as a result."

Definisi ini memberikan batasan bahwa peran aggregator pada dasarnya adalah sebagi supplier pemasok kebutuhan gas kepada konsumen perumahan atau suatu kelompok konsumen dari berbagai golongan masyarakat di suatu kawasan atau daerah tertentu, tanpa dikenakan fee tertentu namun aggregator mengambil keuntungan dari harga jual gas kepada konsumen. Oleh karena itu aggregator adalah penyedia gas yang mendapatkan gas dari berbagai sumber dengan caranya. Karena tidak dikenakan fee, maka harga jual kepada pengguna sudah meliputi harga beli, 
biaya pengangkutan, biaya pembangunan infrastruktur, dan kemasan (Salim, 1999: 54).

Pengertian Aggregator di Indonesia juga bisa ditemukan dengan cara membandingkan atau mengadopsi pengertian aggregator lain yang memiliki tugas dan fungsi mirip seperti Badan Urusan Logistik (BULOG). Kalau Bulog bertujuan utama untuk menciptakan kedaulatan pangan, maka aggregator gas bertujuan utama untuk mewujudkan kedaulatan energi dari sumber energi khususnya gas. Aggregator adalah suatu badan yang bertugas menjamin proporsionalitas, keseimbangan dan keseragaman harga komoditi strategis, dalam hal ini gas, untuk memenuhi kebutuhan atau hajat hidup masyarakat dan bagi industri, serta membuat kebijakan ditribusi dan menyiapkan infrasruktur pendukung, sehingga masyarakat dan pengguna mendapatkan akses yang sama serta harga yang paling murah serta proporsional. Tujuan utamanya adalah agar gas dapat diakses secara mudah oleh seluruh rakyat dengan harga yang proporsional dan mewujudkan fungsi gas untuk mendorong pembangunan yang merata dan adil ke seluruh wilayah negeri.

Uraian di atas adalah definisi yang masih terlalu umum, dengan maksud sekedar untuk memudahkan pembahasan, namun ke depan diperlukan definisi khusus secara legal formil yang sejalan dengan tugas dan fungsi aggregator dalam sistem tata kelola gas. Aggregator gas ini harus bersifat monopolistis atau setidaknya harus di bawah kontrol penuh negara, karena menurut konstitusi Pasal 33 ayat (2) dan ayat (3), gas termasuk dalam golongan kekayaan alam yang bersumber dari alam Indonesia serta menjadi hajat hidup rakyat, maka hanya bisa dikuasai oleh negara. Sehingga pengertian aggregator harus merupakan implementasi dari pengertian "dikuasai" oleh negara sebagaimana diamanahkan oleh konstitusi itu.

Aggregator gas akan menjadi lembaga formil yang masuk dalam sistem kegiatan usaha (bisnis) hilir gas, maka pembahasan akan dimulai dengan menganalisis posisi aggregator dalam perspektif hukum Indonesia. Landasan hukum akan menjadi panduan atau pengarah kebijakan dan sekaligus batasan dalam praktek pelaksanaan. Sehingga keberadaan aggregator harus sejalan dengan kebijakan kedaulatan energi, sehingga tidak bebas nilai dan tanpa misi. Hal ini sesuai rekomendasi Hak Angket BBM DPR RI tahun 2008 yang pada intinya merekomendasikan untuk mengganti UU Migas 2001 dan mengajukan RRU Migas baru yang memiliki pola pikir (mindset) terpenuhinya ketahanan energi nasional sebagai sumber kemakmuran rakyat (Budiyono, 2008: 2).

Payung hukum aggregator dimulai dari peraturan dasar (ground norm) yakni Pancasila, hingga peraturan praktis berupa peraturan-peraturan pelaksana yang relevan. Pancasila, terutama sila ke 5, "Keadilan Sosial Bagi Seluruh Rakyat Indonesia", harus menjadi landasan filosofis pembentukan Aggregator gas. Sila ini menyiratkan keinginan negara untuk mewujudkan demokrasi ekonomi berdasarkan Pancasila yang sering disebut sebagai ekonomi Pancasila. Doktrin ini berbasis kepada kesetaraan hak dan kewajiban bagi seluruh rakyat anggota bangsa 
(Rahardjo, 2008; 23; Mubyarto, 1997: 23). Keadilan sosial adalah cita-cita negara untuk mewujudkan kesetaraan kepada seluruh rakyat Indonesia untuk mendapatkan akses yang sama terhadap kekayaan alam sebagai anugerah Tuhan yang tersimpan di alam Indonesia. Negara tidak membedakan suku bangsa, asalusul, adat istiadat, kemampuan ekonomi, dan strata sosial. Negara memberikan peluang yang sama agar tidak terjadi penguasaan (monopoli) sumber daya alam strategis oleh perorangan, perusahaan, maupun sekelompok orang, sehingga menutup akses serupa terhadap sekelompok yang lain. Intinya, semua rakyat Indonesia memiliki kesempatan dan akses yang sama secara adil dan proporsional.

Berjalannya roda ekonomi dalam sistem ekonomi Pancasila tidak ketat seperti sistem ekonomi etatisme ala Uni Sovyet, tidak pula liberal ala Amerika Serikat (Poepowardojo, 1993: 26; Basr, 1995: 21). Ia adalah kebebasan dengan tanggung jawab, keteraturan tanpa mematikan inisiatif rakyat, mengejar masyarakat adil dan makmur atas dasar landasan demokrasi ekonomi. Karena negara adalah organisasi manusia (rakyat) yang berbeda-beda latar belakangnya, maka tanggung jawab penguasaan atas kekayaan alam strategis dan menguasai hajat hidup rakyat dipercayakan kepada negara dan negara diwajibkan menyelenggarakan dengan cara yang berkeadilan. Sehingga jelaslah bahwa sistem ekonomi Pancasila tidak saja menolak free fight liberalism akan tetapi juga etatisme (ekonomi komando), di mana negara beserta aparatur ekonomi negara mendominasi penuh dan mematika inisiatif rakyat (Pranowo, 2010: 11).

Menurut ekonomi Pancasila, monopoli negara dalam pengertian mengatur dan mengarahkan dengan prinsip keadilan dan kesetaraan, masih dimungkinkan (Widjaja, 2001: 14). Oleh karenanya, aggregator harus menjadi kepanjangan tangan negara untuk mewujudkan harapan negara itu. Kita belum pernah memiliki aggregator gas, namun kita pernah memiliki aggregator dan lembaga sejenis yang dalam prakteknya justru melenceng dan merugikan rakyat. Abdul Hakim G. Nusantara dalam bukunya, Analisa dan Perbandingan Undang-undang Anti Monopoli, menguraikan secara gamblang praktek monopoli dan kartel bisnis yang tumbuh subur dalam ekonomi kita sebelum krisis ekonomi 2009. Pertama, monopoli pengadaan, perdagangan dan olahan tepung terigu oleh PT. Bogasari Flour Mills dan group yang ditunjuk Bulog. Kedua, Asosiasi Semen Indonesia (ASI) yang mendapat monopoli untuk memproduksi dan mengedarkan semen. Perusahaan ini bertindak sebagai kartel dalam pasar semen Indonesia. Ketiga, Aggregator dan Pemasaran Cengkeh (BPPC). Badan ini mendapat monopoli untuk membeli cengkeh dari petani lewat Koperasi Unit Desa (KUD) dengan harga yang sudah ditentukannya secara sepihak. Keempat, monopoli produksi dan hak impor baja oleh PT. Krakatau Steel di Cilegon bersama Salim Group dengan PT. Cold Rolling Mill Indonesia (CRMI) yang menguasai pengadaan baja lembaran. Kelima, Assosiasi panel kayu Indonesia (APKI) yang berfungsi sebagai kartel penjualan kayu. Assosiasi ini memegang hak tunggal memberi lisensi ekspor kayu lapis (Abdul Hakim, 1999; 67). Sehingga pengalaman buruk ini tidak boleh berulang dan merugikan rakyat. Agar tidak mengulangi sejarah buruk di masa lalu, maka rencana pembentukan aggregator gas 
harus disertai analisis yang matang serta berani belajar dari pengalaman untuk selanjutnya membuat aturan yang jelas, tegas dan adil bagi rakyat.

Kegiatan usaha minyak alam dan gas alam yang diatur dalam undang-undang ini berasaskan ekonomi kerakyatan, keterpaduan, manfaat, keadilan, keseimbangan, pemerataan, kemakmuran bersama, kesejahteraan rakyat banyak, keamanan, keselamatan, dan kepastian hukum yang berwawasan lingkungan. Pasal 3 huruf c menyebutkan perlunya menjamin efisiensi dan efektivitas tersedianya minyak alam dan gas alam, baik sebagai sumber energi maupun sebagai bahan baku, untuk kebutuhan dalam negeri.

Undang undang ini juga membagi kegiatan usaha migas ke dalam dua bagian, yakni kegiatan hulu dan kegiatan hilir. Kegiatan Usaha Hilir adalah kegiatan usaha yang berintikan atau bertumpu pada kegiatan usaha pengolahan, pengangkutan, penyimpanan, dan/atau niaga (Kuncoro, 1993: 4). Undang-Undang ini mengatur agar pemerintah menjamin efektivitas pelaksanaan dan pengendalian usaha pengolahan, pengangkutan, penyimpanan, dan niaga secara akuntabel yang diselenggarakan melalui mekanisme persaingan usaha yang wajar, sehat, dan transparan. Untuk menutup kecenderungan atau tabiat binis yanag monopolistis, badan usaha yang melakukan kegiatan usaha hilir tidak dapat melakukan usaha hulu, sehingga kecenderungan monopolistis itu dapat diminimalisir, karena aggregator hanya dapat bergerak di sisi hilir (Kusumo, 2001: 4).

Aggregator gas tidak diatur secara tegas dalam Undang-Undang Nomor 30 Tahun 2007 tentang Energi maupun Undang-Undang Nomor 22 Tahun 2001 tentang Minyak dan Gas. Namun isyarat perlunya aggregator migas bisa disimpulkan dari asas dan ketentuan-ketentuan yang terkandung di dalam kedua Undang-Undang itu. UU Energi menyebutkan bahwa sumber daya energi merupakan kekayaan alam sebagaimana diamanatkan dalam Pasal 33 UUD 1945, dikuasai oleh Negara dan dipergunakan untuk sebesar-besar kemakmuran rakyat. Peranan energi sangat penting artinya bagi peningkatan kegiatan ekonomi dan ketahanan nasional, sehingga pengelolaan energi yang meliputi penyediaan, pemanfaatan, dan pengusahaannya harus dilaksanakan secara berkeadilan, berkelanjutan, rasional, optimal dan terpadu (Marwan Ja'far, 2008: 11; Iwan Paryitno, 2003: 23). Aggregator gas juga harus berlandaskan kepada arah kebijakan energi nasional yang bisa dilihat dari UU Energi tersebut.

Kebijakan energi nasional adalah kebijakan pengelolaan energi yang berdasarkan prinsip berkeadilan, berkelanjutan, dan berwawasan lingkungan guna terciptanya kemandirian dan ketahanan energi nasional (Nazara, 2008; 3). Untuk menciptakan tujuan itu negara telah menetapkan rencana umum energi, yakni rencana pengelolaan energi untuk memenuhi kebutuhan energi di suatu wilayah, antar wilayah, atau nasional.

Aggregator gas juga harus mempetimbangkan hak dan peran masyarakat. Karena UUD 1945, menggariskan bahwa setiap warga negara berhak memperoleh penghidupan layak (Pasal 27). Salah satunya dengan tercukupinya kebutuhan energi dan ketentuan itu diperkuat oleh Undang-Undang energi yang menggariskan bahwa 
setiap orang berhak memperoleh energi. Masyarakat, baik secara perseorangan maupun kelompok, dapat berperan dalam:

a. Penyusunan rencana umum energi nasional dan rencana umum energi daerah;

b. Pengembangan energi untuk kepentingan umum.

\section{PERAN DAN FUNGSI AGGREGATOR GAS}

Semua manusia untuk bisa hidup harus bekerja, untuk bekerja membutuhkan daya, sedangkan daya didapat dari energi, dan gas adalah sumber energi. Gas Alam adalah hasil proses alami berupa hidrokarbon yang dalam kondisi tekanan dan temperatur atmosfer berupa fase gas yang diperoleh dari proses penambangan Minyak dan Gas Alam. Pada skala besar maupun kecil gas sebagai sumber energi diperlukan oleh semua manusia untuk beraktifitas. Namun kenyataannya dari sisi hulu, tidak semua gas didapatkan dengan cara yang sama, ada yang mudah dan ada yang sulit bergantung di mana posisi cekungan tempat di mana gas tersebut berada. Ada yang di darat, di dataran rendah yang mudah diakses, ada yang di pegunungan, dan ada juga yang di tengah hutan belantara yang sulit diakses. Cekungan gas di Indonesia banyak ditemukan di laut lepas (off shore), ada yang laut dangkal ada juga yang di laut dalam (Sanusi, 2001: 23).

Perbedaan-perbedaan itu memiliki konsekuensi kepada cara mendapatkan (ekplorasai maupuan ekploitasi). Untuk di tempat yang sulit tentu dibutuhkan sumber daya dan ahli (expert), tenaga kerja (man power), serta dibutuhkan peralatan dan teknologi yang lebih rumit (complicated). Oleh karenanya, perbedaan lokasi, perbedaan cara, perbedaan kebutuhan alat penunjang, dan perbedaan sumber daya manusia akan membawa akibat kepada perbedaan biaya dan harga.

Gambaran di atas menunjukkan kepada kita beberapa hal yang menjadi perhatian dalam rangka menemukan tata kelola hulu dan hilir gas yang berkeadilan. Jika dilihat dari sisi hulu, tingkat kesulitan eksplorasi dan eksploitasi yang berbedabeda mengakibatkan harga yang berbeda beda pula. Akibatnya kita tidak mungkin memaksa seluruh Kontraktor Kontrak Kerjasama (KKKS) Gas yang kebanyakan adalah perusahaan-perusahaan dari luar negeri (Chevron, Total E\&P, Conoco Philips, CNOOC, CNPC, British Petrolium, Vico Indonesia, Kodeco Energy) untuk menentukan harga jual gas yang dihasilkannya secara seragam. Karena harga ditentukan oleh cara dan biaya untuk mendapatkannya, maka sangat tidak adil kalau kita menyeragamkan harganya, namun juga harga tidak bisa kita serahkan sepenuhnya kepada mekanisme pasar. Dengan demikian dari sisi produksi sudah pasti terjadi perbedaan harga, perbedaan harga menjadi keniscayaan, dari situlah maka terjadi deferensiasi harga dari sisi produksi. Sementara di sisi hilir, lokasi pengolahan gas (pengilangan), kemudahan akses penyaluran untuk membawa gas kepada pemakai, baik perorangan maupun industri, akan membawa konsekuensi kepada pengangkutan laut dan darat (transportation), ketersediaan sarana penunjang distribusi (pipanisasi) dan jumlah kebutuhan gas (demand) yang bergantung dari perbedaan jumlah penduduk, jumlah industry, dan sarana penunjang, kesemuanya akan berpengaruh kepada harga jual. Semakin sulit dan 
panjang rantai distribusi penyaluran, maka semakin tinggi harga jual. Begitupun sebaliknya, semakin mudah penyaluran juga berakibat semakin murah harga jual. Tidak kalah penting adalah besarnya jumlah permintaan atau kebutuhan gas dari masyarakat (rumah tangga) maupun industri (listrik, pupuk, pabrikan, dll) akan berpengaruh juga kepada harga jual. Sehingga baik dari sisi produksi eksplorasi dan ekploitasi (hulu) maupun dari sisi hilir, pengolahan, pengangkutan dan pendistribusian terjadi perbedaan yang berpengaruh kepada harga.

Situasi itulah yang membawa pemerintah, karena kewajibannya, untuk mencari jalan keluar agar disparitas dan deferensi harga baik hulu dan hilir tidak menjadi masalah. Ide tersebut diformulasikan oleh pemerintah dengan cara membentuk aggregator (Public Utilities Reports, 2004: 12). Aggregator menurut pemerintah wajib menjamin ketersediaan dan pendistribusian gas alam sesuai dengan kebijakan energi nasional. Agregator diberi beban untuk menyelenggarakan penyediaan dan pendistribusian gas alam serta konsep pengembangan infrastruktur minyak dan gas alam harus dibangun dengan pemetaan kebutuhan. Pengembangan pembangunan infrastruktur gas alam merupakan syarat bagi pemenuhan gas alam di dalam negeri secara merata dan proporsional. Selain itu, agrregator harus menjamin agar harga gas alam terjangkau oleh konsumen. Untuk harga gas, pemerintah berupaya menghilangkan disparitas harga antara produk LNG dan gas alam (O'Hara, 1999: 44).

Aggregator harus menjamin ketersediaan migas dengan harga yang seimbang (price leader) dan terus berusaha mendekatkan migas kepada konsumen dengan membangun infrasruktur. Tugas aggregator menurut pemerintah sebagai penjelas RUU Migas adalah:

a. Pengaman cadangan gas nasional;

b. Membeli gas alam dari dalam negeri;

c. Membeli LNG dari dalam negeri dan impor;

d. Membangun infrastruktur gas alam;

e. Menjual gas alam di dalam negeri (kepada konsumen dan badan usaha negara)

f. Melakukan aggregasi harga gas alam pada wilayah usahanya.

Pembentukan aggregator juga akan berhadapan dengan UU Persaingan Usaha, mengingat UU Migas sebelumnya meliberalisasi bisnis hilir dan membiarkan pasar mengatur harga keekonomian dengan sistem unbundling dengan persaingan terbuka. Jika harga akan diatur oleh aggregator atas nama kepentingan kolektif, maka banyak perusahaan bisnis hilir akan tumbang karena dipaksa seragam. Padahal diferensiasi harga produk hulu adalah keniscayaan sesuai perbedaan tingkat kesulitan eksplorasi dan eksploitas. Korban yang jatuh tidak hanya Badan Usaha (BU) dan Bentuk Usaha Tetap (BUT), namun juga BUMD yang selama ini diperbolehkan oleh Peraturan Tata Kerja (PTK) BP Migas No. 029-PTK-VII-2009 untuk mendapat gas lewat penunjukan langsung, untuk membantu daerah-daerah penghasil. Mereka tentu memerlukan solusi yang adil. 
Ide-ide pemerintah tentang aggregator tersebut melalui mekanisme konstitusional yang sudah digariskan dalam UUD 1945, terutama Pasal 5 ayat (1) mengatur bahwa Presiden berhak mengajukan rancangan Undang-undang kepada DPR. Pasal 20 menunjukkan bahwa DPR memegang kekuasaan membentuk Undangundang. Setiap Rancangan Undang-Undang dibahas bersama Presiden untuk mendapatkan pengesahan.

Pengusahaan energi meliputi pengusahaan sumber daya energi, sumber energi, dan energi. Pengusahaan energi dapat dilakukan oleh badan usaha, bentuk usaha tetap, dan perseorangan. Pengusahaan jasa energi hanya dapat dilakukan oleh badan usaha dan perseorangan. Pengusahaan jasa energi sebagaimana dimaksud mengikuti ketentuan klasifikasi jasa energi. Klasifikasi jasa energi ditetapkan antara lain untuk melindungi dan memberikan kesempatan pertama dalam penggunaan jasa energi dalam negeri.

Berdasarkan uraian di atas dapat ditarik beberapa pengertian dasar tentang aggregator gas, di antaranya adalah bahwa aggregator akan bergerak menjalankan fungsinya di bidang kegiatan hilir gas dimulai sejak gas dipasarkan ke pasaran dalam negeri. Gas tersebut terdiri dari gas yang dihasilkan dari kegiatan eksploitasi dari sumber dalam negeri maupun gas yang dihasilkan dari impor.

Gas produksi dalam negeri maupun gas yang diimpor dari luar negeri memiliki perbedaan harga beli. Perbedaan ini berakibat kepada perbedaan harga jual kepada konsumen, baik konsumen rumahan maupun perusahaan dan industri. Perbedaan ini berakibat kepada ketidak adilan bagi konsumen yang berdomsili jauh dari pusat supply gas dan belum memiliki sarana distribusi yang memadai, karena mereka akan terkena dampak dari tingginya harga. Terlebih lagi kebijakan distribusi migas selama ini masih terpusat di lokasi-lokasi yang dekat dengan kota-kota besar dan telah memiliki jaringan distribusi. Oleh karenanya, maka negara membentuk aggregator gas yang berfungsi untuk membeli gas dari produsen dari sumber gas dalam negeri dan impor migas dari luar. Gas dari berbagai sumber selanjutnya dijual kepada konsumen dengan harga rata-rata sama kepada konsumen. Untuk menghindari disparitas harga demikian maka pemerintah menetapkan kebijakan kegiatan hilir sebagai berikut:

a. Pemerintah memberikan prioritas terhadap pemanfaatan minyak alam dan gas alam untuk kebutuhan dalam negeri dan bertugas menyediakan cadangan strategis minyak alam dan gas alam.

b. Pemerintah wajib menjamin ketersediaan dan kelancaran pendistribusian bahan bakar minyak, gas alam dan LPG.

c. Pemerintah bertanggung jawab atas ketersediaan infrastruktur untuk mendukung ketersediaan dan keterlancaran distribusi bahan bakar minyak, gas alam dan LPG.

d. Pemerintah menetapkan harga BBM, gas alam dan LPG untuk memenuhi kebutuhan dalam negeri.

e. Pemerintah membentuk/menunjuk Badan Usaha Penyangga Minyak Alam dan BBM (agregator). 
f. Pemerintah membentuk/menunjuk Badan Usaha Penyangga Gas Alam (agregator).

g. Subdisi diberikan kepada yang berhak dan mengarah pada subsidi langsung bukan subsidi harga.

h. Terdapat aggregator/BUMN hilir untuk ketahanan Energi dan pengendalian harga (Price Leader).

i. Sedangkan kelembagaan hilir gas alam, secara lebih khusus diusulkan:

j. Pemerintah membentuk Badan Regulator Hilir Gas Alam.

k. Kegiatan usaha hilir gas alam dilaksanakan dengan Izin Usaha Hilir/penunjukan dari Pemerintah.

l. Pemerintah menunjuk BUMN sebagai Badan Usaha Penyangga Gas Alam Nasional pada wilayah tertentu.

m. Tugas Badan Usaha Penyangga Gas Alam Nasional:

1) Pengaman cadangangan alam nasional.

2) Membeli gas alam dari dalam negeri.

n. Peran serta Pemda dan BUMD:

1) Membeli LNG dari dalam negeri \& impor.

2) Membangun infrastruktur gas alam.

3) Menjual gas alam di dalam negeri (kepada konsumen dan badan usaha niaga).

4) Melakukan agregasi harga gas alam pada wilayah usahanya.

o. BU/BUMD/Swasta/Koperasi dapat menjadi badan usaha niaga untuk kawasan/estate dengan izin usaha dari pemerintah (membeli gas dari agregator).

\section{PENUTUP}

\section{Kesimpulan}

Berdasarkan pembahasan di atas, dapat ditarik beberapa kesimpulan sebagai berikut:

a. Keberadaan aggregator harus sejalan dengan kebijakan kedaulatan energi, sehingga tidak bebas nilai dan tanpa misi. Hal ini sesuai rekomendasi Hak Angket BBM DPR RI tahun 2008 yang pada intinya merekomendasikan untuk mengganti UU Migas 2001 dan mengajukan RRU Migas baru yang memiliki pola pikir (mindset) terpenuhinya ketahanan energi nasional sebagai sumber kemakmuran rakyat. Payung hukum aggregator dimulai dari peraturan idiil (ground norm) yakni Pancasila, hingga peraturan praktis berupa peraturanperaturan pelaksana yang relevan. Pancasila, terutama sila ke 5, Keadilan sosial bagi seluruh rakyat Indonesia, harus menjadi landasan filosofis pembentukan aggregator gas. Sila ini menyiratkan keinginan negara untuk mewujudkan demokrasi ekonomi berdasarkan Pancasila yang sering disebut sebagai ekonomi Pancasila. Doktrin ini berbasis kepada kesetaraan hak dan kewajiban bagi seluruh rakyat anggota bangsa. 
b. Aggregator harus menjamin ketersediaan migas dengan harga yang seimbang (price leader) dan terus berusaha mendekatkan migas kepada konsumen dengan membangun infrasruktur. Tugas aggregator menurut pemerintah sebagai penjelas RUU Migas adalah :

a. Pengaman cadangan gas nasional;

b. Membeli gas alam dari dalam negeri;

c. Membeli LNG dari dalam negeri dan impor;

d. Membangun infrastruktur gas alam;

e. Menjual gas alam di dalam negeri (kepada konsumen dan badan usaha Negara)

f. Melakukan aggregasi harga gas alam pada wilayah usahanya.

\section{Saran}

a. Mengingat fungsi strategisnya sebagai pengendali dan stabilisator komoditi vital, maka perusahaan yang ditunjuk sebagai aggregator tersebut tidak bisa lain harus milik Negara $100 \%$. Pilihan praktisnya aggregator gas dipercayakan kepada badan hukum milik negara yang sudah terbentuk, yakni PT. Pertagas anak perusahaan PT. Pertamina (100 \% saham milik Pertamina), yang sudah mapan bergerak dalam sektor midstream dan downstream industri gas Indonesia, dengan cara "menyapih"nya (spin off) dari PT. Petamina (persero).

b. Pembentukan aggregator juga akan berhadapan dengan UU Persaingan usaha, mengingat UU Migas sebelumnya meliberalisasi bisnis hilir dan membiarkan pasar mengatur harga keekonomian dengan sistem unbundling dengan persaingan terbuka. Jika harga akan diatur oleh aggregator atas nama kepentingan kolektif, maka banyak perusahaan bisnis hilir akan tumbang karena dipaksa seragam. Padahal diferensiasi harga produk hulu adalah keniscayaan sesuai perbedaan tingkat kesulitan ekplorasi dan ekploitas, yang akan menjadi korban tidak hanya Badan Usaha (BU) dan Bentuk Usaha Tetap (BUT), namun juga BUMD yang selama ini diperbolehkan oleh Peraturan Tata Kerja (PTK) BP Migas No. 029-PTK-VII-2009 untuk mendapat gas lewat penunjukan langsung, untuk membantu daerah-daerah penghasil. Mereka tentu memerlukan solusi yang adil.

\section{DAFTAR PUSTAKA}

\section{A. BUKU, MAKALAH, DAN JURNAL}

Basri, Faisal H. (1995) Perekonomian Indonesia menjelang abad ke 21. Erlangga.

LIPI (1977). Cadangan gas bumi di Indonesia: suatu penelitian penjajagan, Proyek Sumber Daya Ekonomi, Lembaga Geologi dan Pertambangan Nasional. Jakarta: LIPI.

Garuda, Abdul Hakim dan Harman, Benny K. (1999). Analisa dan Perbandingan Undang-undang Anti Monopoli di Indonesia. Jakarta: Gramedia. 
Ja'far, Marwan (2008). Energinomic, Ideologi Baru Dunia, Kebijakan Energi Kini dan Esok. Jakarta: Gramedia Pustaka Utama.

Kuncoro, Mudrajat (2009). Transformasi Pertamina: Dilema Antara Orientasi Bisnis \& Pelayanan Publik. Yogyakarta: Galang Press.

Kusumo, Suharto Prawiro (2001). Ekonomi Rakyat: Konsep, kebijakan dan strategi. Jakarta: BPFE UI.

L. Itteilag, Richarg (2012). Natural Gas Future : A World Without Oil. Authorhouse.

Mubyarto (1997). Ekonomi Pancasila : Lintasan pemikiran Mubyarto. Aditya Media.

Nazara, Suahasil, Suryanto, G. Irwan (2008). Memperkuat ketahanan pangan dan energi nasional dalam era persaingan global. Prosiding Sidang Pleno XIII dan Seminar Nasional Ikatan Sarjana Ekonomi Indonesia, Mataram, 17-18 Juli 2008.

O’Hara, Ann (1999). A Practical Guide a gas Contracting. Tusla Oklahama: PennWell Publishing Company.

Partowidigdo, Widjajono (2008). Memperkuat Ketahanan Energi dan Pangan nasional Dalam Era Persaingan Global. Prosiding Sidang Pleno XIII dan Seminar Nasional Ikatan Sarjana Ekonomi Indonesia, Mataram, 17-18 Juli 2008.

Paryitno, Iwan (2003). Dilema Kebijakan Egergi. Jakarta: Pustaka Tarbiatuna.

Sumber Daya Mineral, Kementerian Energi (2015). Peta Jalan Kebijakan Gas Alam Nasional 2014-2030. Jakarta: Direktorat Jendral Minyak dan gas Alam.

Poepowardojo, Soerjanto (1993). Pembangunan Nasional Dalam Perspektif Budaya: Sebuah Pendekatan Filsafat. Jakarta: Gramedia Widiasarana Indonesia.

Pranowo, M. Bambang (2010). Multi Dimensi Ketahanan Nasional. Jakarta: Pustaka Alfabet.

Public Utilities Reports, Volume 235, Lawyers Cooperative Publishing Company, 2004

Pudyantoro, Rianto (2014). Proyek Hulu Migas Evaluasai dan Analisis Petro Ekonomi. Jakarta: Petromindo.

Rahardjo, M. Dawam (2004). Ekonomi Pancasila: Jalan lurus Menuju Masyarakat Adil dan Makmur. Yogyakarta: Aditya Media dan Pusat Studi Ekonomi Pancasila (PUSTE) UGM.

Salim (1999). Kembali Ke jalan Yang Lurus. Jakarta: AlvaBet.

Sanusi, Bachrawi (2004). Potensi ekonomi migas Indonesia. Rineka Cipta.

Tempo, Volume 37, Issues 41-44, Badan Usaha Jaya Press Jajasan Jaya Raya, 2008

Widjaja, Gunawan (2001). Merger dalam perspektif monopoli, Yogyakarta: Raja Grafindo Persada.

Zaenal A. Budiyono (2008). DCSC Pub, Angket dan Paradok Politik. Seputar Indonesia, 2 Juli 2008. 


\section{B. PERATURAN PERUNDANG-UNDANGAN}

Undang-Undang Dasar 1945.

Peraturan Menteri ESDM No.03 Tahun 2010 tentang Alokasi dan Pemanfaatan Gas

Bumi Untuk Kebutuhan Dalam Negeri.

Undang-Undang Nomor 22 Tahun 2001 tentang Minyak dan Gas Bumi

Undang-Undang Nomor 30 Tahun 2007 tentang Energi

\section{INTERNET}

http://www.indonesia-investments.com/id/bisnis/komoditas/gas-alam/item184 diakses pada 22 Desember 2015, Pukul 05:14.

http://katadata.co.id/infografik/2014/07/02/cadangan-gas-indonesia-terbesar-ke14 dunia\#sthash.Zxc4s0Hs.dpbs, diakses pada 22 Desember 2015, Pukul 05:22. http://www.migas.esdm.go.id/post/read/Pertumbuhan-Kebutuhan-Gas-Alam2015-2030-Capai-7-Persen diakses pada 22 Desember 2015, Pukul 16:00. http://www.puco.ohio.gov/puco/index.cfm/be-informed/consumertopics/governmental-energy-aggregation-local-community-buyingpower/\#sthash.9ZJU9uUf.dpbs, diakses pada 12 Maret 2015, Pukul 07.03 http://www.qvinta.com/what-are-energy-suppliers-brokers-and-aggregators diakses pada 1 Maret 2015 jam 6.18

www.bulog.co.id, diakses pada tanggal 23 Maret 2016 